\title{
Primary hyperparathyroidism in pregnancy - a review of literature
}

\author{
Hanna Komarowska, Barbara Bromińska, Bartosz Luftmann, Marek Ruchała \\ Department of Endocrinology, Metabolism and Internal Medicine, University of Medical Sciences, Poznan, Poland
}

\begin{abstract}
Hyperparathyroidism during pregnancy is diagnosed in $0.5-1.4 \%$ women and poses a serious challenge. Symptoms of primary hyperparathyroidism (PHP), namely fatigue, lethargy and proximal muscle weakness, are unspecific and could be mistaken as complaints naturally present during pregnancy. Thus, diagnosis is usually delayed. Moreover, the complications of PHP are very common. They occur in $67 \%$ of mothers and even in up to $80 \%$ of progeny. Appropriate management is a matter of debate. According to clinical symptoms, biochemical evaluation and trimester of pregnancy an operation or conservative management should be introduced. The recognition and understanding of the illness is therefore vital. Due to the lack of unequivocal guidelines concerning pregnancy and PHP, in this review we will analyze recent findings to facilitate proper proceedings.
\end{abstract}

Key words: hypercalcemia, pregnancy, primary hyperparathyroidism, miscarriage

Ginekologia Polska 2017; 88, 5: 270-275

\section{INTRODUCTION}

Calcium plays a vital role in body homeostasis. Calcium-phosphorus balance is mainly regulated via parathormone, calcitonin and vitamin D. The most common reasons of hypercalcemia are primary hyperparathyroidism (PHP) and neoplasms. It is estimated that PHP occurs with an incidence of $1.4 \%$ of the general population. However, more than $80 \%$ of PHP cases remains asymptomatic in both the pregnant and nonpregnant patients and are diagnosed incidentally by review of laboratory data. This disease is present in $0.5-1.4 \%$ pregnant women. In $85 \%$ the cause of the illness is parathyroid adenoma [1]. Symptoms of PHP, namely fatigue, lethargy and proximal muscle weakness, are unspecific and could be mistaken as complaints naturally present during pregnancy [2]. Additionally, physiological changes which occur in women's body in that special time hamper the diagnostics of calcium-phosphorus balance impairment. Hypoalbuminemia, increased filtration rate and active transport of calcium via placenta, reduces the concentration of total calcium in the serum. Estradiol decreases the amount of parathormone (PTH). As a result, hypercalcemia in a pregnant state poses a real challenge for the clinician [3].
Moreover, the complications of PHP are very common. They occur in $67 \%$ of mothers and even in up to $80 \%$ of progeny [4]. Interestingly, neonatal tetany is claimed to be the most common symptom of hyperparathyroidism while pregnancy [5]. It is a real danger for both the woman and her child. Appropriate management is a matter of debate. According to clinical symptoms, biochemical evaluation and trimester of pregnancy an operation or conservative management should be introduced $[6,7]$. The recognition and understanding of the illness is therefore vital. Due to the lack of unequivocal guidelines concerning pregnancy and PHP, we would like to present a review of literature illustrated with two clinical cases in which PHP was diagnosed in completely different circumstances, though ended up with various pregnancy outcomes.

\section{First patient}

A 29-years-old patient in the $21^{\text {st }}$ week of her second pregnancy was admitted to the hospital due to a suspected relapse of Graves' disease and possible adrenal dysfunction. In the $7^{\text {th }}$ week of present pregnancy she complained about weakness, abdominal pains and vertigo. Addition- 


\section{Table 1. Results of the laboratory investigations for the first patient}

\begin{tabular}{|c|c|c|c|}
\hline Week of pregnancy & $13^{\text {th }}$ & $21^{\text {th }}$ & $25^{\text {th }}$ \\
\hline $\begin{array}{l}\text { Cortysole morning } \\
(171-536 \mathrm{nmol} / \mathrm{L})\end{array}$ & 345.4 & 767 & \\
\hline $\begin{array}{l}\text { Cortysole afternoon } \\
\text { (64-327 nmol/L) }\end{array}$ & 143 & 335 & \\
\hline $\begin{array}{l}\text { ACTH } \\
(5.0-60.0 \mathrm{pg} / \mathrm{mL})\end{array}$ & 2.34 & 12 & \\
\hline $\begin{array}{l}\text { Sodium } \\
\text { (135-145 mmol/L) }\end{array}$ & 136 & 135 & \\
\hline $\begin{array}{l}\text { Potassium } \\
(3.50-5.10 \mathrm{mmol} / \mathrm{L})\end{array}$ & 5.56 & 4.85 & \\
\hline $\begin{array}{l}\text { TSH } \\
(0.27-4.20 \mu \mathrm{U} / \mathrm{mL})\end{array}$ & 0.0047 & 1.57 & \\
\hline $\begin{array}{l}\text { FT3 } \\
(3.93-7.70 \mathrm{pmol} / \mathrm{L})\end{array}$ & 6.96 & 4.3 & \\
\hline $\begin{array}{l}\text { FT4 } \\
(11.5-21.0 \mathrm{pmol} / \mathrm{L})\end{array}$ & & 11.79 & \\
\hline $\begin{array}{l}\text { Calcium total } \\
(8.80-10.20 \mathrm{mg} / \mathrm{dL})\end{array}$ & 11.0 & 11.67 & 8.9 \\
\hline $\begin{array}{l}\text { Calcium ionized } \\
(4.2-5.2 \mathrm{mg} / \mathrm{dL})\end{array}$ & & 5.8 & 4.7 \\
\hline $\begin{array}{l}\text { Phosphorus serum } \\
\text { (2.70-4.50 mg/dl) }\end{array}$ & & 3.42 & \\
\hline $\begin{array}{l}\text { PTH } \\
\text { (15.00-65.00 pg/mL) }\end{array}$ & & 74.37 & 18.87 \\
\hline $\begin{array}{l}\text { Urine collection calcium } \\
\text { (100.0-320.0 mg/24h) }\end{array}$ & & 571 & \\
\hline $\begin{array}{l}\text { Urine collection phosphorus } \\
(0.4-1.3 \mathrm{~g} / 24 \mathrm{~h})\end{array}$ & & 1.0 & \\
\hline
\end{tabular}

ACTH - adrenocorticotropic hormone; TSH — thyroid-stimulating hormone; $\mathrm{PTH}$ - parathormone; $\mathrm{FT} 4$ - free thyroxine; $\mathrm{FT} 3$ - free triiodothyronine

ally, the endocrinologist noted gradual drop in the thyroid stimulating hormone (TSH) values from $0.05 \mu \mathrm{U} / \mathrm{mL}$ (the $10^{\text {th }}$ week) to $0.0047 \mu \mathrm{U} / \mathrm{mL}$ (the $13^{\text {th }}$ week) with a rise of $\mathrm{Ft} 3$ to $6.96 \mathrm{pmol} / \mathrm{L}$, and introduced a treatment with a low dose of thiamazole. He also performed tests for adrenal insufficiency. The results were inconclusive (Tab. 1), but the hydrocortisone treatment was introduced. After hydrocortisone supplementation the symptoms alleviated. Patient's complaints about dizziness reoccurred with an attempt to reduce the doses of steroids. Thyroid stimulating hormone receptor antibody (TRAb) levels were within normal value. Past medical records revealed Graves' disease treated successfully with antithyroid drugs 10 years earlier.

Upon admission to the hospital, the physical examination did not reveal any abnormalities. She weighed $59 \mathrm{~kg}$ with the height of $165 \mathrm{~cm}$. Her blood pressure was 110/75, while body temperature $-36.6^{\circ} \mathrm{C}$. The uterus was palpable $2 \mathrm{~cm}$ below umbilicus. An obstetrical ultrasound confirmed a live single intrauterine gestation. The patient complained about heart palpitations. The diagnostics conducted after discontinuation of glicocorticosteroids and antithyroid

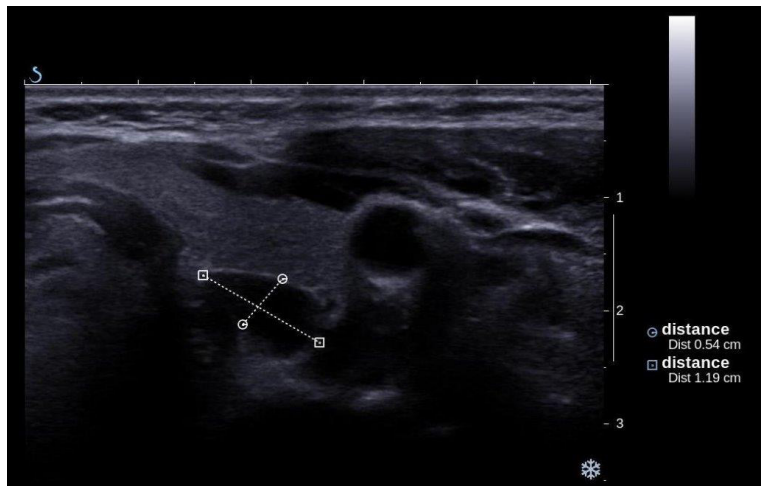

Figure 1. Ultrasound scan of the neck depicting parathyroid adenoma

drugs ruled out both Graves' disease relapse and adrenal dysfunction (Tab. 1). Unexpectedly, we discovered elevated concentration of total calcium. Other tests were performed (Tab. 1). They disclosed raised PTH secretion, hypercalciuria and normal values of phosphorus in the blood and serum. Oral hydration was recommended.

In following weeks, the concentration of PTH, total and ionized calcium were stable, but a decrease in phosphorus in the serum was noticed ( $2.57 \mathrm{mg} / \mathrm{dL}$ ). Corrected calcium levels were $11.35 \mathrm{mg} / \mathrm{dL}$. Ultrasonography of the abdomen revealed nephrolithiasis. We performed ultrasonography of the neck which disclosed a hypoechoic region $10 \times 6 \times 12 \mathrm{~mm}$ under the left thyroid lobe which could be consistent with enlarged parathyroid gland (Fig. 1). Basing on those results, the patient was operated. Surgery was done in the $24^{\text {th }}$ gestation week. The procedure was modified mini invasive parathyroid gland adenoma excision. Because of the pregnancy, we did not use radionuclide guidance. The adenoma of the left inferior parathyroid was successfully dissected and removed. Frozen section pathology and intraoperative PTH assay supported the diagnosis of parathyroid adenoma. A postoperative PTH and calcium evaluation confirmed a curative procedure and the patient was dismissed home on the $3^{\text {rd }}$ postoperative day (Tab. 1). The remainder of her pregnancy was uncomplicated. The women gave birth to a healthy baby girl in the $40^{\text {th }}$ week of gestation. The child did not present any symptoms or abnormal biochemical changes. Apgar scale was 10 in the first and third minute after delivery. The mother visits regularly Endocrinology Outpatient Clinic. The general condition of the patient is very good. Abnormalities in calcium and thyreotropin levels are not observed.

\section{Second patient}

A 28-years-old patient was admitted to the Outpatient Endocrinology Clinic due to hypercalcemia. The women presented previous test results from 18 months before. The concentration of total calcium was increased in every sample (Tab. 2). Medical history revealed miscarriage in the 
Table 2. Results of the laboratory investigations for the second patient

\begin{tabular}{|l|c|c|c|}
\hline & $\begin{array}{c}\text { Before } \\
\text { pregnancy }\end{array}$ & $\begin{array}{c}6^{\text {th }} \text { week of } \\
\text { pregnancy }\end{array}$ & $\begin{array}{c}\text { After } \\
\text { miscarriage }\end{array}$ \\
\hline $\begin{array}{l}\text { Calcium total } \\
(8.80-10.20 \mathrm{mg} / \mathrm{dL})\end{array}$ & 10.861 & 11.39 & 11.1 \\
\hline $\begin{array}{l}\text { Phosphorus serum } \\
(2.70-4.50 \mathrm{mg} / \mathrm{dL})\end{array}$ & & & 2.57 \\
\hline $\begin{array}{l}\text { Urine collection calcium } \\
\text { (100.0-320.0 mg/24h) }\end{array}$ & & 588 \\
\hline $\begin{array}{l}\text { Urine collection } \\
\text { phosphorus } \\
(0.4-1.3 \mathrm{~g} / 24 \mathrm{~h})\end{array}$ & & & 0.94 \\
\hline $\begin{array}{l}\text { PTH } \\
(15.00-65.00 \mathrm{pg} / \mathrm{mL})\end{array}$ & & & 109 \\
\hline
\end{tabular}

PTH - parathormone

$9^{\text {th }}$ week of pregnancy. In that time, the calcium levels were also high. She did not suffer from any other diseases nor took any medications. Her family history did not revealed any significant facts. On the day of the visit in the Endocrinology Outpatient Clinic ultrasonography of the neck was conducted. Under the left thyroid lobe we depicted a hypoechoic region $11 \times 9 \times 8 \mathrm{~mm}$ which could be consistent with an enlarged parathyroid gland. Test results were as follows (Tab. 2). Technetium-99m sestamibi showed an adenoma in the left inferior parathyroid. The patient was referred to the surgical ward in order to remove the lesion. Frozen section pathology and intraoperative PTH assay confirmed the diagnosis of parathyroid adenoma and curative procedure.

\section{DISCUSSION}

\section{Changes in the calcium-phosphorus balance in pregnancy}

The maternal organism undergoes adaptation to provide resources for the developing child. It also concerns the calcium-phosphorus balance. The increased calcium demand is fulfilled by greater absorption in the bowels, kidneys and a higher intake of this microelement [8]. Vitamin D concentration doubles in the early pregnancy and remains on the same level to term. The fetus allocates about $30 \mathrm{mg}$ of calcium in its bones. Deposition occurs especially in the third trimester, during mineralization. Transport of calcium via placenta in the $1^{\text {st }}$ and $2^{\text {nd }}$ trimester is scarce. Total calcium levels are lower, mostly due to hemodilution, decreased albumin concentration and expanded fluid intravascular volume. lonized calcium and phosphorus concentration remains unchanged. From the $12^{\text {th }}$ gestation week the urinal excretion of calcium rises and exceeds normal values. PTH levels are in the low normal range in the first trimester (10$-30 \%$ of mean values for non-pregnant women) and slowly rise to achieve mid-normal at the moment of labour [9].
A vital role in calcium metabolism is played by PTHrP (parathormone related protein). Its concentration greatly increases, especially towards the end of pregnancy. PTHrP is produced in several maternal organs, but also by fetal parathyroid glands. It is postulated that this protein regulates the transport of calcium via placenta to the child and protects the mother's skeleton from demineralization [10].

The knowledge of calcium-phosphorus balance in fetus is scarce. Parathyroid glands originate from the third and fourth parapharyngeal pouch. They differentiate at the $5^{\text {th }}-6^{\text {th }}$ gestational week [11]. The fetal calcium concentrations are up to 0.5 to $\mathrm{mg} / \mathrm{dL}$ higher than the mother's, probably in order to prevent neonatal tetany and support mineralization. Also, the phosphorus levels are greater [12]. Maternal PTH does not cross the placenta (as well as calcitonin), but the fetal parathyroids are probably able to synthetize it since the $10^{\text {th }}$ week. While the concentration of PTH and vitamin D in blood is low, the concentration of calcitonin and PTHrP is high. PTHrP facilitates, relatively independently of the maternal serum calcium levels, the ability of the fetal-placental unit to extract calcium. The secretion of the baby's PTH can be regulated by both the mother's and its own calcium levels. Elevated calcium in the mother's blood can suppress the fetal parathyroid, while maternal hypocalcemia was described to be associated with secondary hyperparathyroidism in neonates [9]. Little is known about the role of the organs normally involved in regulating the calcium-phosphorus balance in adults during embryogenesis. Kidneys are involved in calcium metabolism via the production of small amounts of calcitriol and the regulation of minerals circulation. Intestines probably do not play a vital role [13]. The main purpose of alteration in the maternal mineral metabolism is to support the bone formation in the child. Primary ossification centers develop at the turn of the first and second trimester, but mineralization mainly occurs in the third one [14]. What is important, the fetal skeleton participates in the calcium-phosphorus balance, which means that it is subjected to all the maternal disorders concerning mineral metabolism.

\section{Symptoms and complications}

As mentioned before, the symptoms of PHP are vague. Our first patient complained only about weakness, vertigo and stomach pain. The second one was diagnosed with PHP after a miscarriage which is described as a possible complication of PHP.

Typical manifestations are called „bones, stones, abdominal moans and psychic groans" which can be explained by bony fractures nephrolithiasis, gastritis and mental status changes. Besides those, many other symptoms, such as hypertension, polydipsia, polyuria, confusion, pancreatitis, could occur [2]. In pregnancy, the presentation of PHP 
may be even more confusing. It was shown that hypercalcemia induces preeclampsia [6]. Moreover, Hultin et al. determined that it was particularly parathyroid adenoma that was associated with a higher risk of such complication. The authors suggested that both the entities were linked to insulin resistance and increased cardiovascular risk, thus the association might not be incidental [15]. PHP possibly leads to miscarriage with a 3.5 fold greater risk of such event. Norman et al. examined 78 pregnancies in women with elevated serum calcium levels due to PHP. They noticed 30 miscarriages, especially at the turn of the first and second trimester. Most pregnancy cessations occurred with maternal calcium levels above $11.4 \mathrm{mg} / \mathrm{dL}$. Increasing hypercalcemia was significantly associated with fetal loss rate [16]. Taking into account those studies and lack of serious illnesses in the second case we described, we hypothesize that pregnancy loss in that woman might be attributed to PHP. On the other hand, in a recently published study by Hirsch et al., PHP was not significantly associated with increased rates of abortion or maternal complications. The authors retrospectively reviewed the charts of 74 women who were pregnant while being hypercalcemic. After comparing their pregnancy outcomes with normocalcemic controls, they did not find significant differences. Subsequently, the researchers analyzed the possible existence of variations in the rate of pregnancy-related complications in women who underwent parathyroidectomy and those who did not. The operation was not associated with a lower incidence of abortion or other side-effects of hypercalcemia. What is more, the authors did not disclose a correlation between calcium concentration and complication rates. However, it might be a result of considerably low calcium levels in the cohort [17]. The experienced nausea, dehydration and mental status changes point to the most threatening consequence of PHP which is a hypercalcemic crisis. It may occur during pregnancy, but also after delivery, when active transport of calcium (maternal-fetal gradient is $1: 1.4$ ) via placenta abruptly stops [18].

Fetal complications are present, as it was described before, in up to $80 \%$ of cases. The death of progeny was reported in even $27-31 \%$ of the cases. Other adverse effects are intrauterine growth retardation and low birth weight [7]. On the other hand, Abood et al. investigated 1057 women with PHP and compared their pregnancy outcomes with those of 3171 healthy ones. They did not disclose significant differences between the neonate birth weight, length and Apgar score [19]. Elevated levels of maternal calcium and active transport of this microelement to the baby lead to the suppression of the fetal parathyroid. After labor, when calcium delivery is cut off, the neonate experiences tetany. Although hypocalcemia is usually transient, there were reports of prolonged or permanent illness in children. It was attributed to the adverse effect of hypercalcemia on the third and fourth brachial clefts during organogenesis [20]. To sum up, complicated, symptomatic PHP could pose a threat for the mother and the child's life, unless a proper treatment is introduced.

\section{Diagnosis}

Due to changes which occur in pregnancy (Tab. 3), the diagnosis of PHP is a real challenge for the clinician. This could be a reason for the delayed or missed introduction of the treatment. It is perfectly illustrated by cases we presented. In the study by Norman et al. PHP goes undiagnosed in up to $50 \%$ of pregnant women. Those results were consistent with a research by Hirsch et al. The mean interval from first detection of hypercalcemia to the measurement of PTH was approximately 43 months [17]. The value of the assessment of PTH and total calcium is limited due to physiological decrease in their concentration during pregnancy. Corrected or ionized calcium should be measured. The formula for calculating the corrected calcium is given below.

Corrected $\mathrm{Ca}(\mathrm{mmol} / \mathrm{L})=\mathrm{Ca} \mathrm{mmol} / \mathrm{L}+(0.02 \times(40-\mathrm{al}-$ bumin $\mathrm{g} / \mathrm{L})$ )

An increase in corrected or ionized calcium levels together with PTH above or within high normal range in pregnant women, points to PHP. Other possible reasons of hypercalcemia need to be excluded [21]. After diagnosis, a parathyroid disease should be localized. Routinely employed imaging modalities, namely computed tomography and sestamibi scintigraphy, are to be avoided in pregnancy. The first one due to the exposition to radioactive technetium, the second because of the Röntgen radiation. In this setting, an ultrasonography of the thyroid gland becomes the most important tool to localize a parathyroid lesion [22]. Despite the fact that it has $69 \%$ sensitivity and $94 \%$ specificity in diagnosing an adenoma of the parathyroid, the procedure is highly operator-dependent [23]. To increase the accuracy of the diagnosis, an ultrasound-guided fine needle aspiration biopsy (FNAB) of the suspected lesion may be performed.

Table 3. Changes in the calcium homeostasis during pregnancy

\begin{tabular}{|l|l|}
\hline Measured levels & Pregnant woman \\
\hline Serum calcium & $\begin{array}{l}\text { Total } \downarrow \\
\text { lonized } \leftrightarrow\end{array}$ \\
\hline Urinary calcium & $\uparrow$ \\
\hline PTH & $\downarrow \leftrightarrow$ \\
\hline PTHrP & Progressively $\uparrow$ \\
\hline 25 -vitamin D & $\leftrightarrow$ \\
\hline 1.25-dihydroxyvitamin D & Progressively $\uparrow$ \\
\hline Calcitonin & $\uparrow$ \\
\hline
\end{tabular}

PTH - parathormone; PTHrP — parathormone related protein 
However, it is hard to distinguish thyroid from parathyroid cells by means of cytological examination [24]. PTH levels from needle washouts can be measured. Abraham et al. examined 34 specimens from non-pregnant patients with suspected PHP and compared it with samples from thyroid nodules. PTH levels were significantly higher in PHP than in thyroid lesions. Moreover, the specificity (95\%) and sensitivity (91\%) were very promising [25]. To our knowledge, there are no studies concerning PTH concentrations from FNAB in pregnant women, but it is a safe procedure, when performed by an experienced clinician. There are only few absolute contraindications to FNAB, namely uncorrectable coagulopathy or platelet disorder. PHP should be also suspected when the patient suffers from nephrolithiasis, pancreatitis, hyperemesis, has a history of miscarriage or neonatal problems of progeny with calcium levels.

\section{Treatment}

Optimal management is a matter of debate. The conservative treatment encompasses hydration, oral phosphates, diuretics and low calcium diet. First line proceeding in mild cases should be adequate fluid intake. Parathyreoidectomy or treatment with calcitonin, calcimimetic and bisphosphates are reserved for more serious cases.

Bisphosphates are contraindicated because they cross the placenta and may be associated with fetal skeletal abnormalities, reduced bone growth, weight restriction or hypocalcemia at birth [26]. Losada et al. demonstrated a 20\% rate of congenital abnormalities in children who were exposed to bisphosphates during fetal life [27]. It is possible that above abnormalities will occur even if the mother had received oral bisphosphates before pregnancy [28]. They are retained in the mother's skeleton, so this treatment must be stopped long before the conception $[26,28]$. On the other hand, there are data indicating that bisphosphates do not cause serious adverse events [26]. However, the risk is high, so bisphosphates should not be used in this period.

Calcimimetics has not been widely used in pregnancy. There are only three cases described in literature [29-31]. In two of them, cinacalcet was given only for two weeks before the delivery. The third women, who suffered from parathyroid carcinoma, received cinacalcet throughout pregnancy. Despite the fact that no adverse effects occurred, it is unknown whether cinacalcet is safe for the fetus.

Although calcitonin does not cross the placenta, it is not consider completely safe in this period of a woman's life [32]. Furthermore, calcitonin has limited effect.

Some authors claim that asymptomatic patients with mild hypercalcemia $(<12 \mathrm{mg} / \mathrm{dL}$ ) could be treated without a surgical intervention. Though, such a method requires close medical attention throughout a long period of time. If the mother becomes symptomatic or hypercalcemia aggravates, a surgery is recommended regardless of the gestational age [19]. On the other hand, fetal and maternal complications are difficult to predict basing on the serum calcium levels in the mother. It remains unknown, if mildly elevated calcium levels cause the same rate of complications as higher ones. While other forms of treatment should be taken into account, an operation in the second trimester is still considered the 'gold standard'. Many authors have proved significant reduction of the adverse effects of PHP when operation was conducted, in comparison to the conservative treatment. A review which compares surgery to other treatment methods, has shown the incidence of neonatal complications $10 \%$ vs. $37 \%$, and neonatal mortality $3 \%$ vs. $16 \%$ [33]. Moreover, minimally invasive parathyroidectomy, which is of the same effectiveness as bilateral neck dissection, may be performed. The first method is characterized by a limited operation region, shorter hospitalization time and a smaller scar, as compared to the second one. Thus, it is associated with greater safety and the patient's satisfaction [34]. On the other hand, it should be mentioned that surgery could be dangerous for both the woman and her progeny. A first-trimester operation is to be avoided due to incomplete organogenesis and possible teratogenic effect of anesthetics. A third-trimester surgical treatment poses a risk of pre-term delivery [35]. In both our patients, the operation was finally performed, without any adverse effects.

To conclude, calcium levels should be assessed in pregnant women and in those who have a history of miscarriage. PHP could be suspected when ionized or corrected calcium levels are elevated, while PTH might be within normal range. While computed tomography and sestamibi scintigraphy are to be avoided in pregnancy, an ultrasound scan of the neck should be performed to localize the lesion. When needed, surgery is recommended in the second trimester of pregnancy. Decision concerning the method of treatment should be made by assessing both the clinical status and biochemical blood results. When a conservative treatment is introduced, the mother and her child should remain under strict control. Taking into account possible adverse effect of PHP on the health of both the woman and the fetus, there are growing pro-surgery evidence, regardless of gestational age, but randomized multi-institutional studies are needed to clarify this issue.

\section{Conflict of interest}

There is no conflict of interest that could be perceived as prejudicing the impartiality of the research. 


\section{REFERENCES}

1. McMullen TPW, Learoyd DL, Williams DC, et al. Hyperparathyroidism in pregnancy: options for localization and surgical therapy. World J Surg. 2010; 34(8): 1811-1816, doi: 10.1007/s00268-010-0569-2, indexed in Pubmed: 20386905.

2. Lee CC, Chao AS, Chang YL, et al. Acute pancreatitis secondary to primary hyperparathyroidism in a postpartum patient: a case report and literature review. Taiwan J Obstet Gynecol. 2014; 53(2): 252-255, doi: 10.1016/j.tjog.2013.01.029, indexed in Pubmed: 25017280.

3. Breslau NA, Zerwekh JE. Relationship of estrogen and pregnancy to calcium homeostasis in pseudohypoparathyroidism. J Clin Endocrinol Metab. 1986; 62(1): 45-51, doi: 10.1210/jcem-62-1-45, indexed in Pubmed: 3753557.

4. Kort KC, Schiller HJ, Numann PJ. Hyperparathyroidism and pregnancy. Am J Surg. 1999; 177(1): 66-68, doi: 10.1016/s0002-9610(98)00302-x, indexed in Pubmed: 10037311.

5. Ip P. Neonatal convulsion revealing maternal hyperparathyroidism: an unusual case of late neonatal hypoparathyroidism. Arch Gynecol Obstet. 2003; 268(3): 227-229, doi: 10.1007/s00404-002-0316-5, indexed in Pubmed: 12942255.

6. Hession P, Walsh J, Gaffney G. Two cases of primary hyperparathyroidism in pregnancy. BMJ Case Rep. 2014; 2014, doi: 10.1136/bcr-2013-202883, indexed in Pubmed: 24469844.

7. Scholl TO, Chen $X$, Stein TP. Maternal calcium metabolic stress and fetal growth. Am J Clin Nutr. 2014; 99(4): 918-925, doi: 10.3945/ajcn.113.076034, indexed in Pubmed: 24500145.

8. Salles JP. Bone metabolism during pregnancy. Ann Endocrinol (Paris). 2016; 77(2): 163-168, doi: 10.1016/j.ando.2016.04.004, indexed in Pubmed: 27157104.

9. Kovacs CS, Kronenberg HM. Maternal-fetal calcium and bone metabolism during pregnancy, puerperium, and lactation. Endocr Rev. 1997; 18(6): 832-872, doi: 10.1210/edrv.18.6.0319, indexed in Pubmed: 9408745.

10. Eller-Vainicher $C$, Ossola MW, Beck-Peccoz P, et al. PTHrP-associated hypercalcemia of pregnancy resolved after delivery: a case report. Eur J Endocrinol. 2012; 166(4): 753-756, doi: 10.1530/EJE-11-1050, indexed in Pubmed: 22247017.

11. Lengelé $B$, Hamoir $M$. Anatomy and embryology of the parathyroid glands. Acta Otorhinolaryngol Belg. 2001; 55(2): 89-93, indexed in Pubmed: 11441480.

12. Kovacs CS. Calcium, phosphorus, and bone metabolism in the fetus and newborn. Early Hum Dev. 2015; 91(11): 623-628, doi: 10.1016/j. earlhumdev.2015.08.007, indexed in Pubmed: 26363942.

13. Kovacs CS. Bone development and mineral homeostasis in the fetus and neonate: roles of the calciotropic and phosphotropic hormones. Physiol Rev. 2014; 94(4): 1143-1218, doi: 10.1152/physrev.00014.2014, indexed in Pubmed: 25287862

14. Cox LA. The biology of bone maturation and ageing. Acta Paediatr Suppl. 1997; 423: 107-108, indexed in Pubmed: 9401555.

15. Hultin $H$, Hellman $P$, Lundgren $E$, et al. Association of parathyroid adenoma and pregnancy with preeclampsia. J Clin Endocrinol Metab. 2009; 94(9): 3394-3399, doi: 10.1210/jc.2009-0012, indexed in Pubmed: 19531594.

16. Norman J, Politz D, Politz L. Hyperparathyroidism during pregnancy and the effect of rising calcium on pregnancy loss: a call for earlier intervention. Clin Endocrinol (Oxf). 2009; 71(1): 104-109, doi: 10.1111/j.1365-2265.2008.03495.x, indexed in Pubmed: 19138316.

17. Hirsch D, Kopel V, Nadler V, et al. Pregnancy outcomes in women with primary hyperparathyroidism. J Clin Endocrinol Metab. 2015; 100(5): 2115-2122, doi: 10.1210/jc.2015-1110, indexed in Pubmed: 25751112.

18. Rutkowska J, Bandurska-Stankiewicz E, Matuszewski W, et al. Primary hyperparathyroidism in pregnancy - a diagnostic and therapeutic chal- lenge. Endokrynol Pol. 2015;66(3): 270-274, doi: 10.5603/EP.2015.0034, indexed in Pubmed: 26136136.

19. Abood A, Vestergaard P. Pregnancy outcomes in women with primary hyperparathyroidism. Eur J Endocrinol. 2014; 171(1): 69-76, doi: 10.1530/EJE-13-0966, indexed in Pubmed: 24743398.

20. Som M, Stroup JS. Primary hyperparathyroidism and pregnancy. Proc (Bayl Univ Med Cent). 2011; 24(3): 220-223, indexed in Pubmed: 21738295.

21. Malekar-Raikar S, Sinnott BP. Primary hyperparathyroidism in pregnancy-a rare cause of life-threatening hypercalcemia: case report and literature review. Case Rep Endocrinol. 2011; 2011: 520516, doi: 10.1155/2011/520516, indexed in Pubmed: 22937284.

22. Dochez V, Ducarme G. Primary hyperparathyroidism during pregnancy Arch Gynecol Obstet. 2015; 291(2): 259-263, doi: 10.1007/s00404-0143526-8, indexed in Pubmed: 25367603.

23. Pattou F, Huglo D, Proye $C$. Radionuclide scanning in parathyroid diseases. Br J Surg. 1998; 85(12): 1605-1616, doi: 10.1046/j.1365-2168.1998.00942.x, indexed in Pubmed: 9876061.

24. Agarwal AM, Bentz JS, Hungerford R, et al. Parathyroid fine-needle aspiration cytology in the evaluation of parathyroid adenoma: cytologic findings from 53 patients. Diagn Cytopathol. 2009; 37(6): 407-410, doi: 10.1002/dc.21020, indexed in Pubmed: 19283690.

25. Abraham D, Sharma PK, Bentz J, et al. Utility of ultrasound-guided fine-needle aspiration of parathyroid adenomas for localization before minimally invasive parathyroidectomy. Endocr Pract. 2007; 13(4): 333-337, doi: 10.4158/EP.13.4.333, indexed in Pubmed: 17669707.

26. Stathopoulos IP, Liakou CG, Katsalira A, et al. The use of bisphosphonates in women prior to or during pregnancy and lactation. Hormones (Athens). 2011; 10(4): 280-291, doi: 10.14310/horm.2002.1319, indexed in Pubmed: 22281884.

27. Losada I, Sartori L, Di Gianantonio E, et al. Bisphosphonates in patients with autoimmune rheumatic diseases: Can they be used in women of childbearing age? Autoimmun Rev. 2010; 9(8): 547-552, doi: 10.1016/j. autrev.2010.03.002, indexed in Pubmed: 20307690.

28. Gerin M, Jambon G, Fouque-Aubert A, et al. Neonatal transient hypophosphatemic hypercalciuric rickets in dizygous twins: A role for maternal alendronate therapy before pregnancy or antireflux medications? Arch Pediatr. 2016;23(9): 957-962, doi: 10.1016/j.arcped.2016.03.001, indexed in Pubmed: 27150561.

29. Horjus C, Groot I, Telting D, et al. Cinacalcet for hyperparathyroidism in pregnancy and puerperium. J Pediatr Endocrinol Metab. 2009; 22(8): 741-749, doi: 10.1515/jpem.2009.22.8.741, indexed in Pubmed: 19845125.

30. Rey E, Jacob CE, Koolian M, et al. Hypercalcemia in pregnancy - a multifaceted challenge: case reports and literature review. Clin Case Rep. 2016; 4(10): 1001-1008, doi: 10.1002/ccr3.646, indexed in Pubmed: 27761256.

31. Nadarasa $\mathrm{K}$, Bailey $\mathrm{M}, \mathrm{Chahal} \mathrm{H}$, et al. The use of cinacalcet in pregnancy to treat a complex case of parathyroid carcinoma. Endocrinol Diabetes Metab Case Rep. 2014; 2014: 140056, doi: 10.1530/EDM-14-0056, indexed in Pubmed: 25298882.

32. Diaz-Soto $G$, Linglart $A$, Sénat $M V$, et al. Primary hyperparathyroidism in pregnancy. Endocrine. 2013; 44(3): 591-597, doi: 10.1007/s12020-0139980-4, indexed in Pubmed: 23670708.

33. Kelly TR. Primary hyperparathyroidism during pregnancy. Surgery. 1991; 110(6): 1028-33; discussion 1033, indexed in Pubmed: 1745971.

34. Pothiwala $P$, Levine SN. Parathyroid surgery in pregnancy: review of the literature and localization by aspiration for parathyroid hormone levels. J Perinatol. 2009; 29(12): 779-784, doi: 10.1038/jp.2009.84, indexed in Pubmed: 19587688

35. Walker A, Fraile JJ, Hubbard JG. Parathyroidectomy in pregnancy - a single centre experience with review of evidence and proposal for treatment algorithim. Gland Surg. 2014; 3(3): 158-64. 